\title{
SEGREGAÇÃO SOCIOESPACIAL E VIOLENCIA NA CIDADE DE SÃO PAULO referências para a formulação de políticas públicas
}

Pedro Javier Aguerre Hughes

\begin{abstract}
Resumo: O artigo apresenta a questão da violência, enfatizando a elevada incidência de homicídios nas áreas periféricas da cidade de São Paulo. Analisa o processo de periferização e as formas como o Estado atuou historicamente nessas regiões e indica questões relevantes para a formulação de políticas públicas voltadas à redução da violência e à ampliação da cidadania.

Palavras-chave: políticas sociais; urbanização; criminalidade.
\end{abstract}

Abstract: This article focuses the subject of violence, emphasizing the high incidence of homicides in the outskirt areas of the city of São Paulo. It analyses the out skirting process and the ways the State historically had acted in these areas and indicates relevant points to the public politics of reducing violence and expanding citizenship.

Key words: social politics; urbanization; criminality.

Poder e violência são opostos; onde um domina absolutamente, o outro está ausente. A violência aparece onde o poder está em risco, mas, deixada a seu próprio curso, ela conduz à desaparição do poder. [...] A violência pode destruir o poder; ela é absolutamente incapaz de criá-lo.

Hannah Arendt

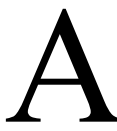
evidência da expansão da violência nos contextos metropolitanos, nas últimas duas décadas, em íntima associação às questões sociais, desvela o percurso histórico de ampliação da desigualdade social, apresentando características diversas de acordo com as especificidades territoriais e urbanas. Por isso, torna-se fundamental ampliar a compreensão a respeito desses espaços urbanos e da complexidade envolvida no fenômeno da violência urbana.

A título de exemplo da expansão da violência,

no Brasil, as mortes por causas externas afetam desproporcionalmente os jovens na faixa etária de 15 a 24 anos, tendo sido responsáveis por $71 \%$ das mortes de homens e
$34 \%$ das mortes de mulheres, nessa faixa etária (ESCOSSIA, 2003).

$\mathrm{O}$ indicador de mortes violentas de jovens (provocada por assassinatos, acidentes de trânsito ou suicídios)

aumentou de maneira generalizada em todo o país, entre 1991 e 2002. No Estado de São Paulo aumentou em 51\% (233,95 mortes para cada grupo de 100 mil habitantes) (RAYMUNDI; KAWAGUTI, 2003).

A situação é mais grave ainda: de acordo com a Organização Mundial da Saúde,

o Brasil é o campeão mundial absoluto em número de homicídios, com uma pessoa morta a cada 12 minutos, ou um total de 45 mil por ano. Com 3\% da população mundial, o Brasil responde por $13 \%$ dos assassinatos. Em 20 anos, a taxa de homicídios cresceu $230 \%$ em São Paulo e no Rio de Janeiro (LOPES, 2003).

Diante dessa realidade, colocam-se em evidência as causas desses fenômenos e, conseqüentemente, as formas 
de combater as manifestações da violência. Estudo do Ipea intitulado Criminalidade: social versus polícia conclui que

a tendência de crescimento do número de assassinatos no país observada nos anos 80 e 90 somente será revertida se houver uma queda da desigualdade de renda no país [...]: no Estado de São Paulo, uma redução de $2 \%$ ao ano na desigualdade da renda faria o número de homicídios cair $11,6 \%$ de 2001 a 2006,

resultado muito superior do que se fossem ampliados progressivamente os investimentos para o aparato policial (GRABOIS, 2003). Com relação a esta constatação, vale acentuar a distinção entre pobreza e desigualdade social, diferenciação que interfere na avaliação da violência. Segundo Pochman (2003), de fato,

o país pode até continuar apresentando queda na taxa de pobreza, como verificado entre 1991 e 2000, sem que isso produza a queda necessária na desigualdade de renda. E, quando isso ocorre, situações correlatas como o desemprego e a violência permanecem 'excluídas' da análise, não transparecendo que são partes pertencentes do mesmo todo complexo e integradas entre si.

Pesquisa recente do Instituto Datafolha sobre combate à violência indicou que

a violência tem de ser prevenida mais pelo combate ao desemprego e melhoria da educação do que pela repressão policial. [...] Dos 12.180 entrevistados, 64\% defenderam o combate ao desemprego e a melhoria na educação como prioridades (PENA..., 2004).

Não é possível, todavia, desprezar o impacto de ações públicas de todos os níveis governamentais sobre as conseqüências da desigualdade social, até porque a violência também se consolidou pela ineficácia histórica da atuação dos aparelhos de Estado. A violência, nesse sentido, deixa de ser uma variável independente, devendo ser considerada uma das manifestações de um conjunto de injunções que comprometem a cidadania e a dignidade humana. Em particular, a violência dos homicídios desvela as contradições da desigualdade social, seja pela polarização social que reflete a concentração da renda, seja pela ausência histórica do Estado nas áreas pobres e desassistidas.

\section{SEGREGAÇ̃̃O SOCIOESPACIAL: URBANIZAÇÃO PERIFÉRICA E O ESTADO}

São Paulo conduziu o processo de urbanização nas últimas décadas segundo o padrão periférico de crescimen- to urbano, que norteou a expansão e consolidação das periferias, gerando uma pluralidade de tempos e circunstâncias de ocupação dessas regiões, marcadas pela heterogeneidade. Em paralelo, os recursos públicos foram canalizados prioritariamente em direção ao desenvolvimento da cidade rica. Esse contraditório processo de desenvolvimento de uma metrópole na periferia do capitalismo levou grande parte dos moradores das periferias, historicamente, à exclusão dos direitos sociais básicos ao trabalho, à saúde e à educação de qualidade, assim como o direito à moradia digna, equipamentos públicos e infraestrutura urbana, o que significou, na prática, um déficit de cidadania e de governabilidade. As contradições verificadas ao longo do processo de urbanização - baseado na autoconstrução, em favelas e loteamentos sem infraestrutura, pautada pela prevalência da especulação imobiliária sobre o direito à cidade - foram denominadas de espoliação urbana, a qual se intensificou em função da dinâmica econômica regressiva nos anos 80 e 90 .

Uma característica fundamental do processo de urbanização foi, portanto, a assimetria entre a localização e as condições sociais, fazendo do ambiente construído espaço privilegiado de expressão das desigualdades sociais, com a permanente pressão dos mais pobres em direção às piores localizações. Desde os anos 80 , as periferias situadas no extremo sul, extremo leste e nas regiões norte e oeste cresceram em 2,3 milhões de habitantes $(71 \%)$, devido às migrações intra-urbanas, passando a responder por $54 \%$ da população da cidade. Nestas regiões, concentram-se os maiores índices de precariedade habitacional e urbana:

A rigor, os processos de segregação socioespacial na cidade estão estreitamente relacionados com a precarização do mercado de trabalho e o desemprego, que afetam mais que proporcionalmente as camadas mais pobres, menos escolarizadas e que tiveram menos meios de resistir àquilo que se pode denominar de diáspora da classe trabalhadora. Este processo, associado à dinâmica especulativa de valorização do solo urbano e aos sentidos do investimento do capital imobiliário, incide sobre as condições e opções de moradia da população, o que, desde os anos 80, leva à expansão demográfica crescente das periferias em contraposição com o esvaziamento populacional nas áreas centrais (bem servidas por infra-estrutura) e à redistribuição das camadas mais ricas da população para novas fronteiras de ocupação delineadas pelos sentidos do investimento do mercado imobiliário (especialmente o quadrante sudoeste) (HUGHES, 2003). 
Historicamente segregada, a cidade informal periférica enfrentou a contingência do déficit dos elementos característicos do pacto subjacente ao contrato social, sendo sua população recorrentemente alijada das decisões e do acesso aos recursos do Estado, apesar da pujança da mobilização e reivindicação dos movimentos sociais, desde o final dos anos 70. Estudos da Secretaria de Habitação indicam a existência de 287 mil domicílios em favelas e 283 mil em loteamentos irregulares de baixa renda, que constituem demanda prioritária que requer intervenção pública. Estes domicílios estão muitas vezes situados em áreas de risco e geralmente apresentam elevados índices de coabitação e adensamento excessivo. É na chamada subregião periférica que se concentram estas modalidades de habitação precária ( $72 \%$ do total de domicílios em favelas e $87 \%$ das unidades habitacionais em loteamentos de baixa renda).

A segregação socioespacial tornou-se, assim, uma marca recorrente na consolidação das periferias, em vista das maiores condições dos segmentos altos e médios da sociedade de disputar as prioridades estatais e o fundo público, relegando-se a um segundo plano as demandas das classes trabalhadoras. É importante observar que as causas da ampliação da precariedade persistem sem que o Estado, em seus diferentes níveis, consiga intervir de maneira estrutural.

As periferias das metrópoles, lugar de maior incidência da pobreza, também concentram a maior parte do desemprego:

dos 7,8 milhões que estavam sem emprego em $2002 \mathrm{em} \mathrm{dez}$ regiões metropolitanas do país, 4,8 milhões pertenciam às familias de baixa renda [...]. Entre 1992 e 2002, a taxa de desemprego média cresceu 38,8\% [...] enquanto na camada mais pobre (famílias com rendimento de até 2,7 salários mínimos mensais) variou 46,8\% (ROLLI, 2004, p. B14).

Outra característica socioeconômica é a intensidade do desemprego dos mais jovens. No Brasil,

os jovens compõem hoje cerca de 50\% do total de desempregados. São quase 7,6 milhões de pessoas que têm de 16 a 24 anos e que estão desocupadas, inativas e fora da escola. Seja pela inexperiência, seja pela baixa inserção educacional, os jovens são as maiores vítimas do desemprego, que pune ainda mais os afrodescendentes e as mulheres (GRAJEW, 2003).

$\mathrm{O}$ desemprego dos mais jovens transformou-se num grave problema social, nos últimos anos, devido à onda jovem, que designa o grande aumento da natalidade no início dos anos 80, gerando, na virada do século, a maior participação relativa de jovens de 14 a 24 anos da história da cidade. Assim, essa geração sentiu muito fortemente o impacto da insuficiência dos serviços públicos - saúde, educação e lazer - e a precarização do mercado de trabalho, durante a década de 90 . A pressão exercida na demanda por serviços sociais é acrescida, dada a idade desses jovens, de uma pressão por alternativas de educação de nível médio e superior (especialmente gratuitos) e oportunidades de emprego, que são as duas alternativas imediatas à vulnerabilidade da desocupação e da vivência cotidiana de uma marginalização imposta socialmente.

A ausência da ação do Estado nas periferias foi uma marca recorrente da urbanização periférica, gerando uma estrutura urbana precária, com insuficientes equipamentos sociais (escolas e postos de saúde) e déficits de infraestrutura e de melhorias urbanas essenciais (como saneamento básico), fruto de uma ocupação desordenada que comprometeu a qualidade de vida, a mobilidade e o acesso da população aos serviços e ao mercado de trabalho.

Além de sua ausência histórica nos investimentos e na melhoria urbana, o Estado também teve uma controvertida presença na vida dos moradores das periferias, pautada por mecanismos de controle social e repressão. Estas formas violentas de atuação, na prática, indicam a existência de duas ordens jurídicas tácitas que diferenciam sua atuação entre regiões periféricas e centrais. Tal reflexão permite contrapor o contrato social que rege as relações sociais na cidade formal e na cidade informal, periférica, sugerindo a recorrência de distinções e diferenciações nas possibilidades de fruição das prerrogativas do Estado de Direito.

Diante disso, reaparece o questionamento sobre a (in)capacidade da modernidade, apropriada pela dinâmica da globalização e do neoliberalismo, de produzir a cidadania e propiciar a emergência de poderes sociais, os quais surgem essencialmente a partir da própria prática política dos movimentos sociais, associações e grupos organizados e da reestruturação da atuação do Estado nas periferias.

Segundo Boaventura de Souza Santos (1998), a crise do contrato social produziu o fascismo do apartheid social.

Trata-se da segregação social dos excluidos, por meio de uma cartografia urbana dividida em zonas selvagens e civilizadas [...] As selvagens são as zonas do Estado de natureza hobbesiano. As civilizadas são as zonas do contrato 
social; vivem sob a constante ameaça das selvagens. Para se defender, tornam-se castelos neofeudais, enclaves fortificados que caracterizam as novas formas de segregação urbana. Nas zonas civilizadas, o Estado age democraticamente, como protetor, ainda que muitas vezes ineficaz ou não confiável. Nas selvagens, age fascistamente, como Estado predador, sem nenhuma veleidade de observância, mesmo aparente, do Direito.

Assim, as periferias recebem um tratamento diferenciado do oferecido à cidade formal no que diz respeito à presença de forças policiais e de segurança pública, sem conseguir atender cabalmente às demandas e reivindicações sociais e nem produzir uma política de segurança pública que dialogue com as percepções e necessidades da população.

Essa controvertida atuação do Estado, associada à amplidão das manifestações da violência, torna-se um dos sinais mais visíveis de uma crise política mais ampla: é preciso

[...] pensar a violência promovida pelo Estado brasileiro, principal detentor do monopólio legal da violência, na medida em que o aparato estatal é também "gerador" de violência (OFICINA DE IDÉIAS, 2003).

\section{AS PERIFERIAS E O FENÔMENO DA VIOLÊNCIA}

A partir dos anos 90, a questão da violência assume centralidade no debate público contemporâneo. O seu crescimento e a ampliação de sua abrangência, especialmente nas regiões metropolitanas de São Paulo e Rio de Janeiro, levaram a uma redefinição do problema como uma das principais questões sociais urbanas, no final do século $\mathrm{XX}$, estreitamente vinculada às condições sociais e urbanísticas desses aglomerados.

A violência nas metrópoles foi, desde logo, vinculada à ascensão do tráfico de drogas e à disseminação de armas de fogo, que se desdobram em diversas manifestações violentas, com diferentes graus de vinculação ao crime organizado. O tráfico, enquanto atividade ilegal, globalizada devido ao destacado papel do Brasil no comércio internacional de drogas, envolve "a estreita interrelação entre o narcotráfico e o comércio ilícito de armas" (VALOR..., 2004):

hoje, no cenário da violência no mundo, não se pode excluir o impacto local do contrabando de armas, que [...] entram ilegalmente em países do chamado Terceiro Mundo, entre os quais o Brasil (ZALUAR, 1998).

Acrescentam-se a isso o capital mobilizado para essas transações e a lavagem de dinheiro, bem como a rede de tráfico de influências requerida para sua operação. No plano da realidade urbana, no entanto, ainda assume importância o consumo voltado preponderantemente para os segmentos médios e altos da sociedade. Para atender a esse mercado, o tráfico se consolida de forma territorializada em determinadas comunidades pobres, gerando inúmeros constrangimentos, como o toque de recolher ou a lei do silêncio. Inversamente, as ações policiais muitas vezes têm impacto negativo, contribuindo para um estado de beligerância e conflito.

A relação entre consumo de drogas, criminalidade e violência urbana foi o tema central do Relatório Anual da Junta Internacional de Controle de Drogas, da Organização das Nações Unidas - ONU. Este documento alerta sobre

o peso que crimes relacionados a elas tem nas cidades do Brasil [...]. Segundo o relatório uma grande parte dos quase 30 mil homicídios cometidos no país anualmente está ligada ao consumo e tráfico de drogas. [...] Pesquisa do Banco Mundial, citada pelo documento, mostrou que "os grupos envolvidos no tráfico de drogas tinham maior nivel de violência do que os que não estavam ligados à atividade” (SCHWARTZ, 2004).

As altas taxas de criminalidade e homicídios são, portanto, um fenômeno que tem se ampliado nas grandes cidades, associado tanto ao tráfico como aos fortes incrementos da pauperização social e da precariedade urbana resultante das transformações no mercado de trabalho e no processo de urbanização. A situação de periferia e de exclusão social, portanto, passa a incorporar vulnerabilidade e riscos advindos de um conjunto complexo de causas e determinantes mais amplos, que afetam, notadamente, crianças e jovens.

Nas duas últimas décadas, como observado por Kilsztajn (2001), o número de homicídios explodiu:

em 1980, de acordo com a Fundação Nacional de Saúde do Ministério da Saúde [...], foram registrados 1.480 homicidios de residentes na Cidade de São Paulo, que equivale a uma taxa de 17,4 homicídios por 100 mil habitantes; em 1999 foram registrados 6.653 homicídios, que equivale a uma taxa de 66,7 por 100 mil habitantes.

De 1999 a 2003, os homicídios, que constituem a segunda principal causa de morte entre os homens, registra- 
ram decréscimo, indicando uma inflexão que precisa ser mais bem estudada e compreendida:

no ano passado, 4.627 pessoas do sexo masculino [ou seja, cerca de $93 \%$ de um total de 4.999 pessoas] foram assassinadas na Capital, segundo dados do Programa de Aprimoramento das Informações de Mortalidade no Municipio de São Paulo - Pro-Aim, da Secretaria Municipal de Saúde (TERRAZ, 2004).

Essa queda pode ser mais bem avaliada pela comparação dos coeficientes de homicídios, entre 2001 e 2003, que variaram negativamente: entre os dez distritos mais violentos, em 2001, os índices situavam-se no intervalo de 117,5 a 75 homicídios por 100 mil pessoas; já em 2003 este valor oscilou entre 88 e 61 por 100 mil habitantes, uma faixa ainda elevadíssima (MAGALHÃES, 2004). Uma particularidade dos homicídios em São Paulo é sua concentração nas áreas periféricas: dez dos 96 distritos da cidade de São Paulo - que apresentam os maiores índices de exclusão social - concentraram $40 \%$ dos assassinatos.

Em 2003, os piores colocados no ranking dos assassinatos, de acordo com Magalhães (2004), foram Guaianases, Brás, Grajaú, Jardim Ângela, Parelheiros, Jardim São Luiz, Cidade Dutra, Marsilac, Parque do Carmo e Sé. Inversamente, os distritos de Moema, Alto de Pinheiros, Jardim Paulista e Perdizes tiveram taxas por $100 \mathrm{mil} \mathrm{ha-}$ bitantes de, respectivamente 1,$46 ; 4,74 ; 6,48$ e 7,05. Destaque-se todavia a presença de distritos das áreas centrais (Brás e Sé), que se caracterizam por amplos contingentes sociais residentes em cortiços de grande precariedade, o que favorece situações de violência, como a dos intermediários que cobram as mensalidades e os conflitos interpessoais agravados pelos constrangimentos da precariedade habitacional.

As áreas com maior presença de violência reduzem as expectativas de vida do conjunto da população:

a expectativa de vida dos moradores de Guaianases (zona Leste), um dos distritos mais violentos da cidade, é 12 anos menor do que a esperança de vida ao nascer dos habitantes de bairros como Jardim Paulista, Consolação e Perdizes (GÓIS; ATHIAS, 2002).

Porém, devem se considerar outras manifestações e enfoques para a delinqüência e a violência, de origem e natureza diversas, que podem ou não orbitar em torno do tráfico, como a disseminação das armas letais e, em determinadas situações sociais, os valores ligados à banalização da vida e à valorização imediatista do consu- mo para alcançar o "respeito" social. A extrema pauperização, evidentemente, contribui para o aumento das agressões e crimes contra a pessoa e o patrimônio. Estas questões, que têm origem eminentemente econômico-social, podem ser aprofundadas enquanto problemas sociais, de forma integrada com ações de segurança pública.

A pesquisa Vidas nuas, mortes banais, ${ }^{1}$ realizada com famílias das vítimas de violência fatal, oferece dados contundentes sobre as condições e motivações dos homicídios: "em São Paulo, a violência dos atos simples dos homicídios está escondida nas suas periferias" (MARSIGLIA et al., 2003).

Os dados mostram como o desenho urbano e os territórios estão relacionados à violência de um modo bastante direto, denotando a vinculação desses eventos aos constrangimentos inerentes às situações de precariedade urbana e à exclusão social, especialmente ao desalento causado pela exclusão social. Mesmo assim, o principal motivador para a exposição ao crime (praticando-o ou sendo vítima) está na venda de drogas:

os meninos passam a ganhar mais que os pais e acabam invertendo a relação de poder dentro de casa (MARSIGLIA et al., 2003).

Envolvidos com o tráfico estão cada vez mais expostos à violência, seja pelas disputas internas de poder entre as organizações criminosas, seja pelos embates com a polícia.

Do total de 3.415 registros de homicídios (entre setembro de 1998 e outubro de 1999), a amostra selecionou 840 que permitiram entrevistar 391 famílias de vítimas de homicídio, a seguir caracterizadas:

São geralmente jovens de 18 a 33 anos, especialmente na faixa de 22 a 25 anos (91\% homens). Seis em cada 10 vitimas nasceram na Capital. $78 \%$ dos bairros visitados não tinham qualquer centro esportivo disponivel para a população. O cinema não faz parte do cotidiano, as pessoas entrevistadas nunca viram, menos ainda o teatro. $81,6 \%$ dos bairros não têm biblioteca. A configuração urbana social e cultural da região facilita o aumento do número de homicidios. A ociosidade nas ruas é muito grande, não tem trabalho, não tem cultura, a distância do Centro é muito grande, a condução é cara, as pessoas ficam nos bairros. $76,5 \%$ das vitimas moravam no bairro há mais de 10 anos; $15,9 \%$ sempre moraram no bairro; $18,6 \%$ tinham passagem pela Febem e 23,2\% já tinham passado por presídio. 22,5\% dessas mortes esperadas eram por dívida de tráfico; $15,5 \%$ por vingança, 
de alguma situação acontecida e 11,8\% estavam juradas de morte. Em 25\% dos casos das famílias estudadas, estas esperavam que a vítima fosse assassinada, a própria vítima já esperava ser assassinada (MARSIGLIA et al., 2003).

Observa-se, portanto, que há condicionantes sociais que devem ser considerados na formulação de políticas públicas mais adequadas para a redução dos conflitos fatais. Apesar da importância da questão do tráfico e de sua flagrante ilegalidade, as medidas de penalização poderiam considerar a realidade social dos jovens envolvidos, "aviões, olheiros ou noinhas" - que por vezes têm apenas tênue vínculo com o comando e estão distantes da execução de ações violentas.

\section{LIMITES DAS POLÍTICAS DE SEGURANÇA PÚBLICA NAS PERIFERIAS}

A ação das forças de segurança pública, especialmente das polícias, como citado anteriormente, não está dissociada da explosão da violência criminal e da consolidação de redes de tráfico de drogas em torno de bairros pobres, situações essas que, favorecidas pela ausência do Estado, produzem formas de poder baseadas na coerção e no constrangimento das comunidades residentes em assentamentos precários.

A especificidade dos órgãos de segurança pública relaciona-se ao seu caráter especial de detentores legais dos meios de exercício da violência, de que o Estado detém o monopólio legal, delegando a aplicação das respectivas competências junto à sociedade civil. A transição da ditadura à democracia, de forma "lenta, gradual e segura", não assegurou suficientemente a discussão da natureza e dos objetivos das instituições do Estado, apesar da Constituição de 1988. Dessa forma, a política de segurança pública expressa e reafirma, para o bem e para o mal, esse Estado que representa. Essa implicação recíproca alcança, de maneiras diversas, os diferentes níveis do Estado, implicando, além do poder Executivo, o Judiciário e o Legislativo.

A questão da segurança pública, assim, não deve ser analisada separadamente da sociedade urbana com as características daquela aqui analisada, em que o Estado não desenvolveu instrumentos amplos de inclusão econômica, urbanística e social.

As mortes de civis pela polícia, que batem recordes ano a ano, expressam uma política e estratégias próprias de um Estado autoritário, mostrando a dissociação entre ação policial e realidade social.
Como esses organismos foram estruturados na perspectiva da repressão politica e policial, ficam bastante evidentes as raizes históricas da violência policial: a violência policial fatal cometida por PMs de São Paulo, que vitimou, de 1990 a março de 2000, 6.565 pessoas (MARIANO, 2000).

Em 2003, foram registradas

756 mortes em confronto com PMs em serviço, [que] representam um recorde anual nas estatísticas desde 1996 [...]. Em 2002, foram 541 mortes; em 2001, 385 (PENTEADO, 2004).

Levantamento da Ouvidoria das polícias Civil e Militar, de 2000, mostrava que

$51 \%$ das pessoas que tinham sido mortas nessa situação tinham sido baleadas pelas costas (PENTEADO, 2003).

Segundo Hélio Bicudo (apud PENTEADO, 2003), “a violência policial é incentivada pelo Estado", sendo assim "é claro que ela vai aumentar".

Referindo-se à realidade do Rio de Janeiro, Luis Eduardo Soares (2001) toca na questão da percepção das violências observadas no cotidiano das favelas:

a comunidade é submetida, em seu cotidiano, a duas formas de opressão, a tirania do tráfico e o despotismo da polícia. Ambos são temidos, causam horror e repugnância, mas o segundo é considerado mais grave, porque não segue qualquer regra, qualquer código de conduta que permita a elaboração de estratégias de sobrevivência eficientes.

É importante, portanto, problematizar um padrão repressivo de ação das forças policiais, favorecido pelo desaparelhamento do sistema judiciário, que aparece como elemento historicamente recorrente nas estratégias voltadas à resolução de conflitos nas periferias. Uma questão que pode ser trabalhada nesta direção é a renovação dos regulamentos que legitimam a atuação repressiva, propiciando uma revisão estrutural das polícias.

Parece essencial considerar as periferias como espaços cidadãos, extremamente populosos e carentes da presença do Estado que, como tais, requerem a presença de juízes, promotores, delegados:

por que não temos, por exemplo, em São Mateus, na Zona Leste de São Paulo, um juiz de direito, um promotor público, um delegado de polícia morando lá, em vez de residir nos Jardins? Deveriam dar o expediente lá, morando lá, porque essa regra de o juiz morar na sua circunscrição judiciária é regra constitucional não obedecida (BICUDO, 1997, p. 71). 
De fato, a pesquisa Vidas nuas, mortes banais apurou também a dificuldade que essas famílias têm em acessar a justiça, por razões econômicas ou falta de conhecimento, e que gostariam de poder confiar no Estado para não precisarem "fazer justiça com as próprias mãos" ou viver com medo de represálias: com relação aos processos, 59,3\% das famílias não se mostraram satisfeitas com o desfecho (muitos casos são arquivados pela justiça por falta de provas ou porque o suposto réu morreu).

Em 27,5\% dos casos as famílias não sabem o que aconteceu com o processo; só $16 \%$ foram procuradas pela polícia para informações depois do homicídio, o que mostra que os homicídios são registrados e esquecidos lá, não há uma investigação que vá apurar as causas da morte (MARSIGLIA et al., 2003).

Em $47 \%$ dos casos não foi instaurado o processo judicial, em 7,4\% o processo foi arquivado, só se encontraram $9,4 \%$ dos casos em andamento:

foram analisados 296 processos no fórum: 82\% foram arquivados ainda na fase de inquérito, ou na fase processual, 4\% encontraram algum desfecho na justiça. Nos 296 homicídios, entretanto, apenas 7 réus foram condenados (MARSIGLIA et al., 2003).

\section{POLÍTICAS PÚBLICAS DE ENFRENTAMENTO DA VIOLÊNCIA}

A questão dos crimes e da violência é mais tratada como problema policial do que social. Embora a questão das drogas esteja na agenda governamental em tentativa de modernização, incorporando conceitos de redução de danos, de descriminação do porte de drogas para uso individual e pautando a integração das ações em segurança pública, o debate do tema deve superar desde logo o enfoque estritamente repressivo, incorporando outros aspectos.

É preciso apontar aqui o desafio de compreender que a associação da violência às condições sociais de pobreza não significa uma tendência ou predisposição dos pobres à violência, pois isto corresponde a uma dupla penalização das populações periféricas. Nos anos 90, segundo Zaluar (1998),

a generalização de imagens da cidade como um ambiente violento e os sentimentos de medo e insegurança dela decorrentes passaram a fazer parte do cotidiano dos seus moradores, mas atingiram particularmente os que vivem nas favelas e bairros pobres alimentando os círculos viciosos da violência cotidiana em que os pobres tornam-se os mais temidos e os mais acusados, justificando a violenta e injusta repressão que sofrem.

O enfoque tradicional legitima a via da reclusão dos envolvidos em crimes, que recai forçosamente sobre os mais pobres, independentemente da natureza dos crimes cometidos. Com isto, tanto jovens como adultos, eventualmente de baixa periculosidade, conduzidos à reclusão, passam a conviver com violências e coerções que podem (e tendem) conduzi-los a envolvimento com grupos organizados, dívidas, achaques, delações, etc. A pesquisa aqui apresentada sobre vítimas de violência mostrou, de fato, que $18,5 \%$ das vítimas de homicídio haviam passado pela Febem e 23,2\% pelo sistema prisional, o que é um percentual muito alto.

A estigmatização dos jovens envolvidos naturaliza as práticas que colocam como única alternativa de punição os sistemas correcionais disponíveis, em vez de outras possibilidades mais adequadas, especialmente para os crimes menos graves, como a liberdade assistida ou outras previstas no Estatuto da Criança e do Adolescente - ECA.

Embora outras manifestações de violência, como a vitimização de crianças e adolescentes, de gênero e até mesmo os crimes banais estimulados por circunstâncias específicas, como o uso de álcool e drogas, atravessem as diferentes classes sociais, é possível que tenham maior incidência nas regiões de maior exclusão social, devido aos múltiplos constrangimentos e tensões cotidianas envolvidos.

As referências a respeito da violência criminal não diminuem a importância de se entender a violência comum, cotidiana, da exclusão social, que alarma e violenta os moradores das periferias. Trata-se da violência das situações que desgastam a auto-estima, tais como a precariedade habitacional e urbana, o acesso precário à saúde, especialmente para tratamentos complexos ou para obtenção de remédios, a falta de vagas na educação infantil e no ensino médio, a violência no trânsito (que também é intensa na periferia), bem como a precária mobilidade e as dificuldades de acesso aos bens e serviços disponíveis nas áreas consolidadas, devido ao custo dos transportes.

A violência criminal, cumpre destacar, tem um impacto psicossocial muito significativo, pois nas periferias quase todas as famílias vivenciaram ou conhecem relatos de situações de violência muito próximas. No caso da pesquisa de Marsiglia et al. (2003), verifica-se que 56\% das vítimas deixaram filhos, muitos dos quais assistiram 
a morte dos pais. Ou seja, não há mais como enfrentar a violência unicamente sob a ótica da criminalidade - apresenta-se um novo caminho em que compreendê-la como forma de expressão dos conflitos e interesses diversos é essencial.

Segundo a Oficina de Idéias (2003), o desafio é tecer esse conceito e, a partir desse ponto, construir uma nova maneira de lidar com a problemática, elaborando estratégias e ações que considerem essa nova visão do problema, pois

numa dimensão ela [a violência] é realidade alheia e hostil à realização mais plena das tentativas democratizantes $d a$ sociedade em todos os níveis (da marginalização do pequeno criminoso até a repressão militar de conflitos trabalhistas), [assim como em outros aspectos, ela é] expressão limite de articulações culturais dinâmicas, a opção para reivindicar exigências sociais justas, a forma de apresentar novas identidades culturais ou ressimbolizar a situação de marginalidade, dando, assim, início a uma tentativa de superação da exclusão social.

Mucchielli sugere que, para entender a violência, devese considerar que

parte importante da delinqüência urbana seja sempre ligada à questão das desigualdades sociais, sobretudo nas sociedades que se querem democráticas e que pretendem que cada um possa aceder à riqueza e ao consumo (POBREZA..., 2002, p. A-17).

Se na realidade esse "sonho moderno" é reservado apenas a uma parte da população, a outra parte às vezes será submissa e resignada, mas às vezes será rebelde e violenta.

Marilena Chauí (1986, p. 56-57) amplia a análise para toda a sociedade, pontuando a existência de mecanismos de diferenciação social e urbanística entre classes sociais:

sem sombra de dúvida, o padrão de moradia reflete todo um complexo processo de segregação e discriminação presente numa sociedade plena de contrastes acirrados.

De fato,

com a fragmentação ou declínio dos espaços politicos, as expressões da violência são uma espécie de "avesso do político enfraquecido" e indicam, de certa forma, uma perda, déficit ou ausência de conflito, expressando uma defasagem entre as demandas subjetivas de grupos ou pessoas e a oferta politica, econômica, institucional ou simbólica: a violência é a voz do sujeito não reconhecido, rejeitado e prisioneiro da massa desenhada pela exclusão social e pela discriminação racial (WIEVIORKA apud OFICINA DE IDÉIAS, 2003).

Considerando a reflexão desenvolvida, verifica-se que o principal aspecto que incide na redução da violência é a inclusão social e o desenvolvimento econômico, como indicado pela pesquisa conduzida pelo Ipea. Não menos importante é a governabilidade, entendida como a presença do Estado, através do fortalecimento das políticas sociais - educação e saúde - e da gestão estatal cotidiana nos territórios. Porém, a presença do Estado deve ser integradora das ações nos diferentes níveis governamentais e explorar intensamente a inter-setorialidade, com intensa participação social e envolvimento das redes de atores sociais ligados à dinâmica social e política das regiões periféricas. De fato, a eficácia das ações não pode prescindir da participação social, desde a identificação dos problemas a serem enfrentados, até o planejamento das ações concretas e o controle social de sua implantação. É possível verificar uma enorme diferença na apropriação coletiva de espaços modificados segundo investimentos governamentais, em função do grau de participação e adesão dos segmentos sociais beneficiários da ação.

A auspiciosa redução da violência mortal indicada pelos dados apresentados pode ser entendida como resultado de múltiplas causas.

Porém, dadas as prerrogativas das políticas públicas no âmbito municipal e o longo interregno em que, durante os anos 90, as questões sociais foram relegadas e a política econômica levou centenas de milhares de pessoas ao desemprego e à informalidade - ocasionando uma brutal precarização das condições de vida nas regiões mais pobres -, há que se reconhecer a importância das ações conduzidas por esse nível de governo.

A descentralização político-administrativa, criando as subprefeituras, a disseminação da inclusão digital nas periferias ou a experiência dos Centros de Educação Unificada são exemplos que apontam para a viabilidade de reduzir a distância entre Estado e sociedade nas regiões mais precárias, restituindo os poderes sociais da comunidade no embate com as formas de violência institucionalizadas. A consolidação desta nova realidade, ampliando os mecanismos de participação social na gestão descentralizada das políticas, poderá representar um novo marco na inflexão das injunções históricas nesses territórios, que levaram a violência a esse padrão epidêmico.

Têm importância na redução da violência também a ampliação do policiamento preventivo e comunitário, reforçado pela reestruturação da Guarda Municipal e cria- 
ção da Secretaria Municipal de Segurança Urbana, que desenvolve experiências de formação de Comissões Civis Comunitárias, em subprefeituras que apresentam altos índices de violência (identificando e encaminhando demandas que a população percebe como fontes de violência).

As periferias foram estruturadas de forma desordenada, propiciando, assim, a constituição de situações que configuram uma verdadeira "arquitetura da violência" (LEITE, 2004), em que habitações precárias, falta de iluminação, áreas abandonadas, estruturas viárias caóticas, organizadas sem a presença do Estado, possibilitaram o desenvolvimento de espaços favoráveis às manifestações de violência.

O Projeto Bairro Legal, desenvolvido pela Secretaria de Habitação, em parceria com a instituição Cities Alliance, produziu, sob coordenação metodológica do Laboratório de Habitação e Assentamentos Humanos da FAU-USP, uma proposta metodológica e planos de ação, renovando as abordagens de planejamento para a melhoria habitacional. Coordenado por Ermínia Maricato e, em seguida, por João Whitaker, teve como um de seus resultados a reflexão denominada "A Violência Urbana e o Plano de Ação Bairro Legal”, em que aprofunda o papel da qualificação habitacional na diminuição da violência (LABHAB/FAU-USP, 2003).

Este projeto contribuiu na identificação das demandas prioritárias junto à população e às diversas instâncias do poder público envolvidas na perspectiva do diagnóstico das condições sociais e habitacionais e da qualificação dos espaços, com intervenções integradas que atuem sobre as manifestações de violência. Estes planos foram desenvolvidos no Jardim Ângela, Brasilândia e Cidade Tiradentes, em função do elevado grau de exclusão social e violência.

No âmbito da melhoria urbanística e habitacional, a transformação dos assentamentos precários em bairros integrados à cidade, garantindo a segurança na posse (impedindo a reintegração sumária de glebas ocupadas e regularizando favelas em áreas públicas e loteamentos), reconstrói enclaves precários, adequando a infra-estrutura e propiciando o atendimento aos serviços básicos e as políticas públicas essenciais.

Um destaque específico deve ser dado aos programas sociais implementados pela prefeitura de São Paulo, que estão contribuindo para a diminuição da violência na cidade, mais especificamente com impacto na redução do número de homicídios. Um estudo realizado pela Secre- taria de Desenvolvimento, Trabalho e Solidariedade indica que,

nos treze distritos atendidos pela secretaria desde 2001 houve queda de 21,8\% na taxa de homicídio por $100 \mathrm{mil}$ habitantes, enquanto nos 37 locais atendidos desde $2002 \mathrm{o}$ decréscimo foi de 16,6\%, no período de 2001 a 2003. Já nos distritos que ainda não contam com os programas sociais, a redução foi menor, de 10,4\% (SALGADO, 2004).

Cabe observar que os 13 distritos atendidos eram os mais pobres e violentos da cidade.

Verifica-se, portanto, que, para além das condicionantes macroeconômicas que impedem a inflexão nas tendências históricas de ampliação da desigualdade social, há caminhos para desenvolvimento de políticas públicas que incidam na redução dos homicídios. Trata-se de amplo leque de políticas públicas sociais e de qualificação habitacional e urbana que envolvem e atingem as camadas mais vulneráveis à violência. Tudo leva a crer que, ao serem implementadas, associadas a mecanismos progressivos de descentralização do poder e à ampliação da participação social, se reduz a violência. Estas constatações permitem retornar à assertiva apresentada na epígrafe, no sentido de que a criação de poderes sociais tem a potencialidade de se sobrepor progressivamente à presença da violência territorializada, colocando em xeque a normatividade do tráfico de drogas e a criminalidade organizada, que teria estendido sua ação para além das fronteiras naturais de seus "negócios". Outro aspecto relevante é a necessidade de rediscutir as políticas de segurança pública, reduzindo as mortes de civis e superando uma concepção de que constituiriam uma espécie de esfera institucional autônoma - essencialmente repressiva. Voltando o Estado a se fazer progressivamente presente, através de políticas sociais e da restauração de sua importância na gestão da vida social nas áreas periféricas, torna-se necessária, portanto, a integração das ações dos distintos níveis governamentais para o combate às causas dessa violência, colocando lado a lado todos os agentes públicos que incidem sobre essa realidade, exatamente como acontece na divisão de prerrogativas das diferentes esferas estatais na cidade rica e estruturada. Acima de tudo, onde se criam condições para o exercício do poder, na gestão da vida das comunidades periféricas, junto ao poder público, as organizações sociais e a população crescentemente organizada, ganha-se espaço da violência instituída e se avança na direção, apenas aparentemente paradoxal, da institucionalização da presença do Estado nas áreas mais necessitadas. 


\section{NOTAS}

Artigo desenvolvido a partir da tese de doutorado do autor, intitulada "Periferia: um estudo sobre a segregação socioespacial na cidade de São Paulo" (HUGHES, 2003).

1. A apresentação pública da pesquisa foi gravada e transcrita em 08 de julho de 2003.

\section{REFERÊNCIAS BIBLIOGRÁFICAS}

ARENDT, H. Sobre a violência. Relume Dumará, [s.d.].

BICUDO, H. A violência e a estrutura judiciária brasileira. Estudos Avançados, v. 11, n. 30, p. 71, 1997.

CHAUÍ, M. Conformismo e resistência: aspectos da cultura popular no Brasil. São Paulo: Brasiliense, 1986.

ESCÓSSIA, F. da. Violência atinge mais as mulheres jovens. Folha de S.Paulo, São Paulo, 18 dez. 2003. Disponível em: $<$ http://www1.folha.uol.com.br/fsp/cotidian/ff1812200320.htm>.

GÓIS, A.; ATHIAS, G. Área violenta reduz expectativas de vida. Folha de S.Paulo, São Paulo, p. C-3, 23 abr. 2002.

GRABOIS, A.P. Criminalidade só cai com melhor distribuição de renda, diz Ipea. Folha de S.Paulo, São Paulo, 2 ago. 2003.

GRAJEW, O. Os filhos do Brasil. Folha de S.Paulo, São Paulo, 23 jul. 2003.

HUGHES, P.J.A. Periferia: um estudo sobre a segregação socioespacial na cidade de São Paulo. 2003. Dissertação (Doutorado) - PUC, São Paulo, dez. 2003.

KILSZTAJN, S. Óbitos por agressão/Sistema de informações sobre mortalidade: Brasilândia, Cidade Tiradentes e Jardim Ângela. São Paulo: PMSP/Sehab, 2001 (Projeto Bairro Legal).

LABHAB/FAU-USP. Metodologia consolidada para a elaboração de planos de ação habitacionais e urbanos. São Paulo, PMSP/Sehab/ Habi - Cities Alliance - Banco Mundial, jul. 2003. (Projeto Bairro Legal).

LEITE, P.D. Obstáculo urbano cria nicho para o crime. Folha de S.Paulo, São Paulo, p. C-1, 11 jan. 2004.

LOPES, C. Soberania nacional e execuções sumárias. Folha de S.Paulo, São Paulo, 6 nov. 2003. Disponível em:

$<$ http://www1.folha.uol.com.br/fsp/opiniao/fz0611200310.htm>.

MAGALHÃES, R. Guaianases: bicampeão de homicídios. Jornal da Tarde, São Paulo, 10 fev. 2004.

MARIANO, B.D. Controle social dos excluídos e a polícia. Folha de S.Paulo, São Paulo, 8 maio 2000. Caderno Opinião, p. 1-3.
MARSIGLIA, R.M.G.; PAVEZ, G.A.; CASTANHA E OLIVEIRA, I. de M. Vidas nuas, mortes banais. São Paulo, 2003. (Pesquisa CRAVI - PUC-SP)

OFICINA DE IDÉIAS. Uma proposição metodológica de protagonismo juvenil. São Paulo: PMSP/ Sehab/Habi - Cities Alliance Banco Mundial, maio 2003. (Projeto Bairro Legal).

PENA de morte é defendida por 50\%. Folha de S.Paulo, São Paulo, 1 jan. 2004. Disponível em: <http://www1.folha.uol.com.br/fsp/ cotidian/ff0101200406.htm>.

PENTEADO, G. Governo erra número de mortos pela PM. Folha de S.Paulo, São Paulo, 3 fev. 2004.

Mortes de civis pela polícia batem recordes. Folha de S.Paulo, São Paulo, 31 jan. 2003. Caderno Cotidiano, p. C-3.

POBREZA ainda explica crime, diz o sociólogo francês Laurent Mucchielli. Folha de S.Paulo, São Paulo, 3 fev. 2002. Caderno Mundo, p. A-17.

POCHMANN, M. Menos pobre, muito mais desigual. Folha de S.Paulo, São Paulo, 5 nov. 2003. Disponível em:

$<$ http://www1.folha.uol.com.br/fsp/dinheiro/fi0511200310.htm>.

RAYMUNDI, V.; KAWAGUTI, L.M. Número de mortes violentas de jovens cresce em 51\% em São Paulo. Diário de S.Paulo, São Paulo, 18 set. 2003

ROLLI, C. Taxa de desemprego cresce mais entre ricos. Folha de S.Paulo, São Paulo, p. B-14, 20 fev. 2004

SALGADO, R. Programas sociais ajudam no combate à violência. Diário de S.Paulo, São Paulo, 27 fev. 2004.

SANTOS, B. de S. Os fascismos sociais. Folha de S.Paulo, São Paulo, 6 set. 1998. Caderno Tendências/Debates.

SCHWARTZ, C. Grande parte de homicídios no Brasil tem relação com drogas - ONU. Folha de S.Paulo, São Paulo, 3 mar. 2004. Disponível em: <http://noticias.uol.com.br/inter/reuters/2004/03/ 03/ult27u40967.jhtm>.

SOARES, L.E. A ética e o intelectual no século XXI. In: ROITMAN, A. O desafio ético. Rio de Janeiro: Garamond, 2001.

TERRAZ, R. Homicídio é a segunda causa de mortes de homens em São Paulo. Diário de S.Paulo, São Paulo, 19 fev. 2004.

VALOR político de controle das drogas cresce na América do Sul. Folha de S.Paulo, São Paulo, 2 mar. 2004.

ZALUAR, A. Para não dizer que não falei de samba: os enigmas da violência no Brasil. In: SCHWARCZ, L.M. História da vida privada no Brasil. São Paulo: Cia. das Letras, 1998. 4 v.

Pedro Javier Aguerre Hughes: Sociólogo, Doutor em Ciências Sociais, Coordenador do Programa "URB - AL Rede 10: luta contra a pobreza urbana” da Prefeitura de São Paulo. 